\title{
A Comparison of Inter-Organizational Business Models of Mobile App Stores: There is more than Open vs. Closed
}

\section{Roland M. Müller ${ }^{1}$, Björn Kijl ${ }^{2}$ and Josef K. J. Martens ${ }^{3}$}

${ }^{1}$ Berlin School of Economics and Law, Department of Information Systems, roland.mueller@hwr-berlin.de University of Twente, School of Management and Governance, ${ }^{2}$ b.kijl@utwente.nl,

3 j.k.j.martens@alumnus.utwente.nl

Received 16 January 2011; received in revised form 17 April 2011; accepted 18 May 2011

\begin{abstract}
The purpose of this paper is to analyze the competition among mobile app stores for smart mobile media devices. Therefore, the business models of seven mobile app stores are analyzed with a special focus on Apple and Google. We use e3-value modelling - a formal business modelling technique - for analyzing the critical elements of these mobile ecosystems. The analysis of the app store ecosystems allows a differentiated view on the different strategies of the app store owners. Additionally, we look at the impact of network effects, economies of scale, platform differentiation, quality assurance, and transaction costs on the design of mobile application markets. This theoretical model allows a deeper discussion about the design choices and success factors in the different app store cases. Based on our analysis, we expect that the open versus closed models discussion becomes less relevant - so-called open platforms have closed aspects as well as the other way around - and that competitive differentiation and segmentation strategies will become increasingly critical in order to strengthen the competitive positioning of the different app store platforms.
\end{abstract}

Keywords: App stores, Business models, Mobile software markets, Mobile application markets, Open vs. closed business models, E3-value modelling 


\section{Introduction}

After the introduction of the Apple App Store in July 2008, competitors rushed to introduce their own mobile software markets. In April 2011, Distimo (Site 1) - a Dutch mobile application (app) store analytics company-discovered at least 56 different mobile app stores (see Table 1 for a subset). They can be classified into mobile app stores from device manufacturers, OS and software platform developers (this includes Java and Chrome), telecommunication operators, component manufacturers, and independent app stores. Some of these app store providers can also be placed in multiple categories.

Table 1: Overview of mobile app stores (based on Site 1)

\begin{tabular}{|l|c|c|c|c|c|}
\hline & $\begin{array}{l}\text { Device } \\
\text { Manufacturer }\end{array}$ & $\begin{array}{l}\text { Operating } \\
\text { System } \\
\text { Developer }\end{array}$ & $\begin{array}{l}\text { Network } \\
\text { Operator }\end{array}$ & $\begin{array}{l}\text { Component } \\
\text { Manufacturer }\end{array}$ & Independent \\
\hline Apple App Store & $\mathrm{X}$ & $\mathrm{X}$ & & & \\
\hline $\begin{array}{l}\text { RIM, Blackberry App } \\
\text { World }\end{array}$ & $\mathrm{X}$ & $\mathrm{X}$ & & & \\
\hline Nokia Ovi Store & $\mathrm{X}$ & $\mathrm{X}$ & & & \\
\hline Palm App Catalog & $\mathrm{X}$ & $\begin{array}{l}\text { (X) (Only for Bada } \\
\text { Operating System })\end{array}$ & & & \\
\hline Samsung Apps Store & $\mathrm{X}$ & & & & \\
\hline LG Application Store & $\mathrm{X}$ & & & & \\
\hline $\begin{array}{l}\text { Dell Mobile Applications } \\
\text { Store }\end{array}$ & & $\mathrm{X}$ & & & \\
\hline Google Android Market & & $\mathrm{X}$ & & & \\
\hline Windows Marketplace for \\
Mobile
\end{tabular}

Mobile application stores are very attractive for these organizations for several reasons. On the one hand, they promise tremendous growth. Gartner (Site 2) estimates the overall mobile application stores revenue at $\$ 6.2$ billion in 2010 and $\$ 29.5$ billion in 2013. On the other hand, mobile application stores are crucial in the competition of mobile platforms. The success of a mobile platform depends on the successful design of a viable mobile ecosystem of related services and components [5].

In this paper we used mainly two research methodologies: first, a concise literature review based on related papers on mobile app markets and platform competition; second, a cross-case analysis of the seven currently most popular app stores. For this analysis, a theoretical model was developed based on economic concepts relevant for app store analysis, like network effects and platform differentiation. The cross-case analysis itself was based on published information like press releases, trade press, developer or market licences, and market analyses: For some markets, 
we registered and used the app store as a buyer as well as a potential app developer. By combining a focus on academic work through the literature review, the development of a theoretical model, and a relatively strong focus on market and industry research reports and other public information like press releases for the cross-case analysis, we hope to contribute to both research and practice.

As the main method for structuring and analyzing our observations, we used the concept of inter-organizational value networks modelled with the e3-value methodology [17]. An e3-value model can be seen as a graphical representation of a business model because it represents the main value and money streams and related value network roles. We also used economic theories about network effects, economies of scale, platform differentiation strategies, and transaction costs. These analytical tools form the basis for our theoretical model of mobile app stores. In combination with the value network design, this theoretical model allows a deeper discussion about the design choices and success factors in the different app store cases.

We begin the paper by reviewing relevant prior work in mobile app store and platform competition research. After describing related work, in Section 3 we develop the theoretical model needed for the analysis. We do so by using economic theories like network effects, (dis)economies of scale, platform differentiation strategies, transaction costs, and information asymmetries. Then we will analyze the business models of mobile app stores and design a generic inter-organizational app store value network based on the e3-value approach. In Section 4, we analyze the influence on the elements of the generic e3-value model for app stores through seven examples. Finally, based on the crosscase analysis, we draw conclusions about a more differentiated view of open vs. closed business models for app stores.

\section{Related Work}

This paper focuses on competition between mobile app store platforms. Mobile app stores can be seen as a critical component of mobile platforms. In this section, we will concisely summarize related research on platform competition and mobile app stores before introducing the theoretical concepts and theoretical model used for our mobile app store platform cross-case analysis.

Platform Competition. A platform is a set of stable elements (e.g., physical components, operating-system software, standards) that allow the development of interchangeable, complementary components [5], [20]. Examples of platforms are VHS, Microsoft Windows, Facebook, and the Apple iPhone. The success of a platform depends to a large extent on the variety and quality of complementary components. Microsoft Windows was successful because it had the largest number of applications available compared to other operating systems. Boudreau [5] analyzed the effect of three different platform strategies: a) having a closed platform, b) opening the platform for complementary services, and c) giving up the control of the platform. He analyzed the effect of these platform strategies for 21 handheld computing systems on new device development between 1990 and 2004. He found that strategy b produced a fivefold increase in new handheld devices compared to strategy a. Strategy c still had a positive effect but was an order of magnitude smaller.

Mobile App Stores. Even though mobile app stores are essential in the competition between mobile platforms, so far only a few prior scientific papers have been published on this topic. Lin and Ye [23] presented a food web analysis of different key players in the mobile industry. However, Lin and Ye [23] do not use any formal business modelling technique, such as e3-value modelling, as we did. Also, they do not focus on the role of app stores. Schlagwein, Schoder and Fischbach [35] analyzed the openness of different mobile platform elements. They distinguish between access to a resource (open, group, exclusive) and control of a resource (internal, shared, external). Gonçalves, Walravens, and Ballon [16] distinguish between two dimensions of mobile platforms: control over assets (yes/no) and control over customers (yes/no). This leads to four different platform types: an enabler platform (control over assets but no control over customers; example: Intel), a system integrator platform (control over assets and customers; example: Microsoft Windows), a neutral platform (neither control over assets nor over customers; example: PayPal), and a broker platform (no control over assets but control over customers; example: eBay). Gonçalves et al. [16] apply their platform typologies to mobile network operators.

\section{Theoretical Model}

After introducing several theoretical concepts relevant for app store analysis-i.e., network effects, economies of scale, platform differentiation, transaction costs, quality assurance, and business models-a value model of the Mobile App Store Ecosystem will be presented in this section. This model will form the basis for the cross-case analysis as described in Section 4. By combining relevant economic theories and formal e3-value modelling, the different aspects of mobile app stores can be better analyzed compared with a single theoretical frame.

Network Effects Platforms often exhibit two-sided network effects [34]. App developers prefer a mobile platform with many end users, and end users prefer a platform with many apps. This positive-feedback effect makes a mobile app store with more customers and developers more valuable for both sides [12]. However, indirect network effects for 
app stores might decline because a) the marginal utility diminishes with the number of apps and b) more apps might decrease the chance of finding the right one [12].

Economies and Diseconomies of Scale. The development of a mobile app store requires substantial up-front investments as well as fixed costs that are independent of the number of buyers and sellers. Therefore, we can expect economies of scale for mobile app stores; the average cost for serving more buyers and sellers is decreasing with more buyers and sellers. However, at some point there might also be diseconomies of scale. With many apps on the market, it could be very difficult for an end user to find the right app. Therefore, techniques to reduce these search costs are necessary. Also, a platform that tries to appeal to all user segments and use scenarios might be inferior for some end users and app developers compared with more specialised platforms.

Platform Differentiation and Multihoming. Diseconomies of scale might open the possibility for platform differentiation [12]. Mobile platforms can differentiate on the level of quality and price (vertical differentiation) or on the user segment (horizontal differentiation) [12]. For example, Research in Motion is focusing on the business user segment. Some developers want to address all potential customers. In this case, developers might decide to develop their apps for different mobile platforms, a phenomenon called multihoming [34]. Dominant platform owners might discourage multihoming to preserve their leading position. For example, in April 2010, Apple changed their developer agreements in a way that prohibits cross-platform compilers for iPhone apps (Section 3.3.1 of the iPhone Developer Program License Agreement, April 2010). However, in September 2010, Apple removed these restrictions (Section 3.3.1 of the iPhone Developer Program License Agreement, September 2010).

Transaction Costs. One role of an electronic market is to reduce the transaction costs for buyers and sellers. The interaction process of a market can be divided into several transaction phases [36]. We distinguish between the information phase, the agreement phase, the execution phase, and the after-sales phase. In each phase, different transaction costs occur (see Figure 1).

By examining the different transaction phases, it is possible to analyze the transaction costs for the participants that arise when entering the market [40]. The analysis of the transaction costs indicates whether any transaction within the market is actually beneficial for the participants [41].

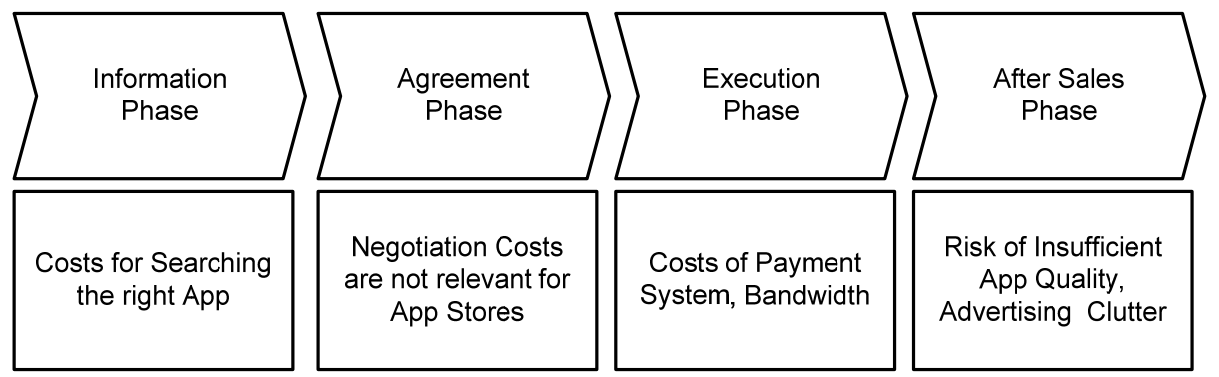

Figure 1: Transaction phases and their transaction cost for an end user

In the information phase, the end user attempts to get information about apps (such as quality and relevance). Some risks are shielded away by the mobile app store, such as the risk that the application developer might not deliver the application at all. Because the app store has a copy of the app, delivery is guaranteed. Therefore, the end user is not very concerned with the reputation of the seller as it is in the case of auction markets like eBay. The app store might also prescreen apps for malicious side effects (like Trojan horses). If an app store is not prescreening apps, the reputation of sellers becomes more important for the buyer. High transaction costs occur during the information phase because of the search time needed for finding the right app. Rating, matching, and recommendation services can lower these costs.

In the agreement phase, buyers and sellers negotiate the conditions of the transaction. This phase ends with a legally binding contract. Most app stores have fixed prices, and the only choice end-users have is whether to take it or leave it. Also the mobile application store has standardized terms of business for the seller and buyer. Both elements will lower the transaction costs of the agreement phase compared with a nonstandardized agreement phase. An interesting innovation in the negotiation step is offered by the upcoming independent Android app store from Amazon. Unlike other app stores, where developers can set a take-it-or-leave-it price, Amazon determines the price of an app. The app developer can set a list price, which is the price the developer normally wants to set for the app. The price is automatically adjusted based on various market factors. The developer receives 70 percent of the sales price. The developer is guaranteed to receive at least 20 percent of the list price if Amazon deeply discounts the app or offers it for free [21].

In the execution phase, the contract is fulfilled, and the goods and services are exchanged. In this phase, the app is transferred and the money is paid. The transaction cost consists of bandwidth costs and cost of the payment platform. All activities after the execution phase happen during the after-sales phase. There is a risk that the app 
does not have sufficient quality. Quality assurance services such as customer reviews, ratings, and guarantees can reduce this risk.

Quality Assurance. Apps are experience goods, which mean buyers can evaluate the relevance and quality of an app only after the purchase. App stores should assure quality before reception because recipients are unwilling to search and pay for apps of unknown quality. The seller, however, has more information about the quality of the apps. This kind of asymmetric quality information could lead to a "market for lemons" [2]. The effect would be that poor quality crowds out the higher quality. There are several mechanisms to overcome quality uncertainty. In the following, we will analyze the appropriateness of the following quality mechanisms for app stores: reputation building, reputation systems, guarantees, previewing, and pre-screening.

Reputation Building. Building up a reputation is an inducement for a provider not to act opportunistically [38]. A provider's reputation rests on having an uninterrupted series of transactions with a positive outcome. By maintaining a series of transactions with the same app buyer, a developer has an incentive not to act as an opportunist. However, an app purchase between the same buyer and seller is typically a one-time event. Therefore the likelihood of coming across the same app seller more than once is very low, and building up a reputation in this way will make little sense for the app seller. Opportunistic behaviour of sellers is alleviated to a certain extent in electronic marketplaces when a critical mass of buyers and sellers interact frequently and thus have a mutual interest in long-term quality assurance.

Reputation Systems. Reputation building can be further promoted by a reputation system that aggregates ratings of other market participants regarding the quality of apps and makes them public among the potential buyers [11], [13], [19], [33]. In this way, a potential buyer evaluates an app in the form of a grade system and comments every time a transaction takes place. Public ratings discourage opportunistic behaviour of the app developer, even if the app developer is not likely to interact with the same buyer more than once.

Guarantees. Money-back guarantees are an often-used means of increasing a buyer's confidence beforehand. However, as it is difficult for a buyer to return an app, there is a danger that guarantees will be abused. Opportunistic behaviour of buyers can be expressed as a misuse of guarantees.

Previewing. In previewing, the potential buyer can get part of the good for inspection, e.g., a trailer for a motion picture [38]. Previewing an app can be done by allowing the buyer to use the app for a certain time at no cost or with a reduced feature set. Many apps have a free version with the possibility to buy more features, such as games where certain levels are free to play. This can be described as a freemium strategy. This strategy is additionally supported if the app store allows in-app-purchases of, for example, virtual goods or game levels. One problem with previewing is that it is difficult to ensure that a prospective buyer does not receive too much functionality so that there is no longer any need to proceed with the purchase. Until December 2010, Google Android Market had a 24-hour purchase refund window. This allowed buyers to test an app without the risk of buying an unusable or low-quality app. However, for some applications, such as small games, users can experience the complete game and then get a refund. In December 2010, Google reduced the purchase refund window to 15 minutes.

Pre-screening. Reviewing is one form of quality testing that has been established for scientific publications and patents [38]. An article may be published or a patent awarded only after a review has been made by other experts. Apps can be appraised in the same way by a third party before they get published on an app marketplace. The prescreening can also be a check for security threats. However, app quality is not just a binary construct, but more of a continuum between totally unusable and very good user experiences. Therefore, the definition of a threshold is subjective and makes the prescreening process unpredictable for the app developer. This is especially problematic because many app stores are the only venue to sell legitimately to mobile phone buyers. Additional disadvantages of prescreening are that it is costly and adds latency between the submission of the app and the publication on the app store.

To summarize, app quality can best be enhanced through a reputation system consisting of public ratings and previewing capabilities. Prescreening is most valuable for discovering security risks.

Business Models. The term 'business model' was one of the great buzzwords of the Internet boom-bust cycle during 1998-2000. All a company needed at that time was a web-based business model that promised wild profits in a distant future [24]. In most business model definitions, we can recognize the assumption that a business model should describe the business logic behind value creation with a specific product or service [24]. The business model concept may support simulating, analysing, and understanding current or new business ideas and exploiting these ideas [29], [30]. During the 1970s, the business model concept was mainly used for describing IT-related business processes [22], [37]. More recently, the business model concept has been used for analysing market structures as well as strategic choices related to positioning of organizations within these market structures [6], [9], [18], [32]. A widely used business model definition within this context is that of Chesbrough and Rosenbloom [8], who define a business model as "a blueprint for how a network of organizations co-operates in creating and capturing value from technological innovation", like mobile service innovation. 
Initially, telecom operators tried to manage and control the complete value chain, while today multi-actor value networks are a much more common structure for developing and exploiting mobile services [31]. The i-mode closedwalled garden approach to mobile service commercialization, as introduced in 2002 by the Dutch telecom operator KPN, was not viable [10]. However, Apple's app store can be seen as a successful implementation of essentially the same kind of approach. Google's more open Android concept is successful as well. Next to business model innovation on a services platform level, application developers are also currently experimenting with different 'in app' business models, such as offering free apps where products and services can be purchased within the app (e.g., new levels, new magazines, or attributes for games).

As of yet there is no consensus regarding business model components - some researchers focus on revenue models only, whereas others have a broader perspective and also look at concepts like value propositions and technological architectures when describing or analysing business models. However, recent work by Al-Debei and Avison [3] on developing a unified framework of the business model concept identifies four primary value dimensions or components: value-proposition (offering value structure), value-architecture (technological architecture and organizational infrastructure), value-network (business and customer actors web), and value-finance (financial setups and returns). These dimensions resemble the ones as identified by Bouwman et al. [6] and Osterwalder et al. [29], [30].

E3 Value Model of the Mobile App Store Ecosystem. With more technological possibilities, companies are increasingly struggling on this level of business model innovation instead of on the level of technological innovation [7]. The mobile services value network is modelled with the e3-value approach [39]. We used the 3-value modelling because it offers a fine-grained view on the interdependencies between different value activities and actors of the mobile ecosystem. The elements of the business ecosystem are derived from our cross-case analyses of different mobile app stores as described in Section 4.

The business model is represented in Figure 2 according to the e3-value notation standard [17]. It shows the relations between the different value-network roles of the mobile app stores, connected by the value exchanged during each actor's value activity. Value transactions always have a starting and an ending point, connected through activities. The individual actors as depicted in Figure 2 are described in Table 2. The transactions involve the exchange of money and/or information about end users in exchange for information goods. The goods exchanged can be licenses, network connections, software, or advertisements.

Table 2: App store ecosystem value network roles

\begin{tabular}{|l|l|l|}
\hline $\begin{array}{l}\text { Value Network Role } \\
\text { Name }\end{array}$ & Description & $\begin{array}{l}\text { Example (of Value } \\
\text { Network Actor) }\end{array}$ \\
\hline End User & The owner of a smartphone & You \\
\hline Network Operator & The supplier of a network connection for smartphones & T-Mobile \\
\hline Payment Broker & $\begin{array}{l}\text { The supplier of information regarding (credit card) } \\
\text { payments }\end{array}$ & $\begin{array}{l}\text { PayPal, Amazon, Visa, } \\
\text { American Express }\end{array}$ \\
\hline Advertisement Broker & The supplier of advertisements for in applications & AdMob, Microsoft, Yahoo \\
\hline Marketplace Engineer & The owner of the app store & SlideME, Apple \\
\hline $\begin{array}{l}\text { Operating System } \\
\text { Developer }\end{array}$ & The developer of the OS & Apple, Microsoft, Google \\
\hline $\begin{array}{l}\text { Testing \& Verification } \\
\text { Signing Partner }\end{array}$ & $\begin{array}{l}\text { The third party assigned with testing \& verification of } \\
\text { software }\end{array}$ & Sogeti HT \\
\hline Software Developer & The third party supplying a signing certificate & VeriSign \\
\hline Content Provider & The software provider & Larva Labs, Layar \\
\hline Software Distributor & $\begin{array}{l}\text { The software aggregator, intermediating in providing } \\
\text { software }\end{array}$ & EA Games \\
\hline Device Manufacturer & $\begin{array}{l}\text { The designer and manufacturer of the smartphone } \\
\text { hardware }\end{array}$ & Samsung \\
\hline
\end{tabular}

The owner of a mobile app store can perform one or more acting roles in the value network. This allows for a differentiation between mobile app store owners. The span of control for roles in the value network allows for capturing single or multiple revenue streams, maximizing money inflow and minimizing money outflow. In the generic mobile app store value network as shown in Figure 2, the main money inflow is created by end users consuming software and advertisement brokers supplying advertisements. Money outflow is dominated by payouts to individual software developers and software distributors. A mobile app store owner can influence the value inflow and outflow by designing the value network and offering value activities different from those of competitors. 


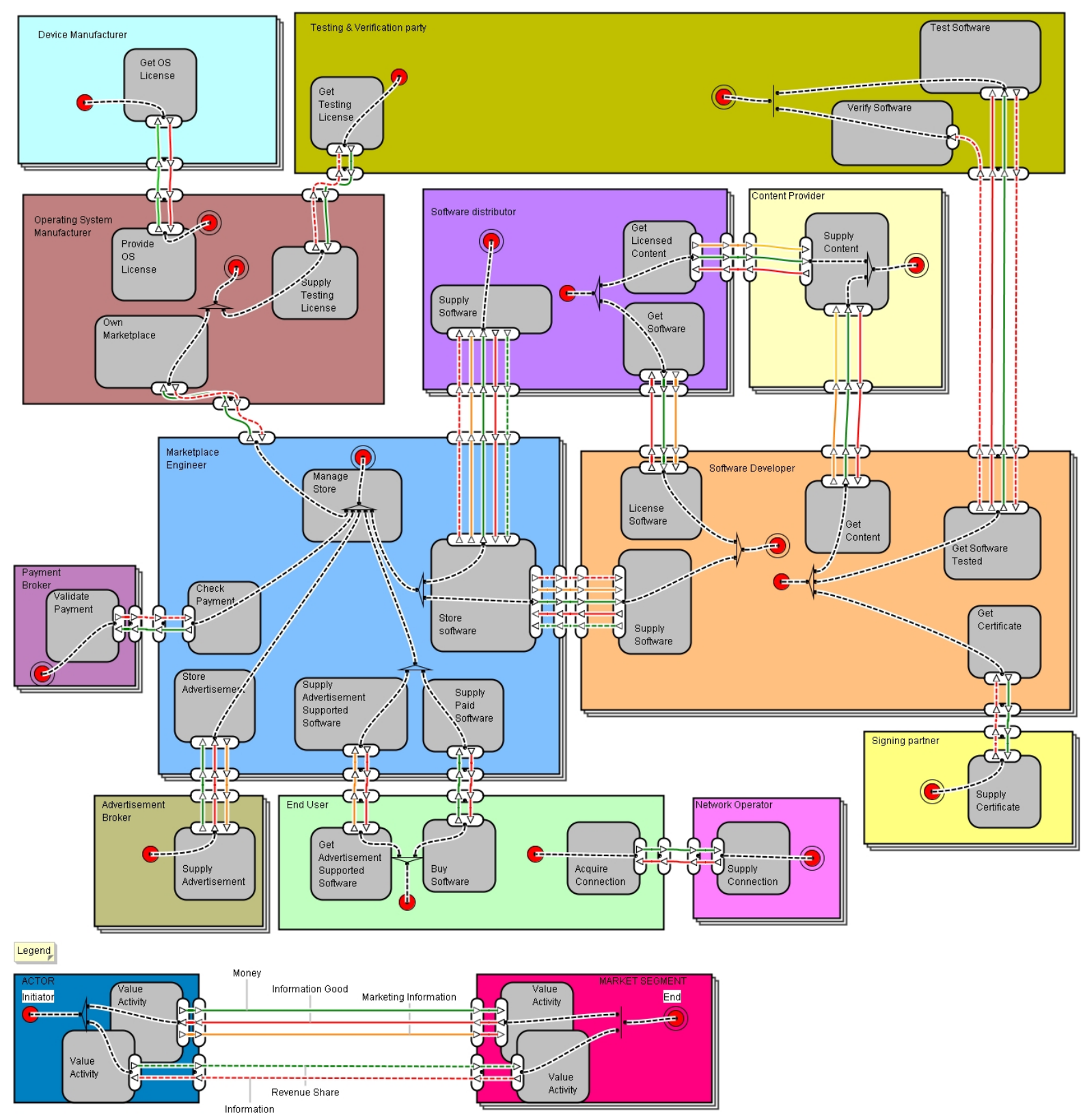

Figure 2: Mobile app store value network (e3 value modelling)

\section{Mobile App Stores Case and Cross Case Analysis}

In this section, we will concisely discuss the differences between the business models of seven mobile app stores: Apple, Research in Motion (RIM) Nokia, Samsung, Google, Microsoft, and GetJar (see Table 3). Special attention is paid to Android and Apple, the two biggest app stores. The case selection was based on the size of the market, the available information, and the coverage of different app market types. 
Table 3: Market figures for App Stores (April 2011) (Site 1)

\begin{tabular}{|l|r|r|}
\hline & \# of apps & \# of downloads \\
\hline Apple App Store & 350,000 & (Site 3) 10 Billion \\
\hline RIM (BlackBerry App World) & 22,130 & [4] 3 million per day \\
\hline Nokia Ovi Store & 54,024 & $\begin{array}{r}\text { (Site 4) 5 million } \\
\text { per day }\end{array}$ \\
\hline Samsung Apps & 3,187 & (Site 5) 100 Million \\
\hline Google (Android Market) & 135,829 & (Site 6) 3 Billion \\
\hline Microsoft (Windows Phone 7 Marketplace) & 8,723 & \\
\hline GetJar & 17,749 & 899 Million \\
\hline
\end{tabular}

Apple entered the smartphone industry in 2007 with the iPhone. In 2010, the iPhone had the fourth-largest market share of the smartphone industry [15]. Nearly all of the value-network actor roles are covered by Apple for the iTunes App Store. The only exception is the mobile network connection, which is necessary for end users to utilize their smartphones with $3 \mathrm{G}+$ connectivity. Apple influences this value-network role through contracts with network operators for one to two years of exclusive distribution in return for a revenue share on the monthly charges towards end users.

Research in Motion, the smartphone company from Canada, started in 1996 with an alternative device for communication that was a two-way pager designed for text communication. With the addition of voice communication technology, the BlackBerry was released in 2002 with push e-mail as a distinctive feature, allowing instant response possibilities. BlackBerry devices are sold with complementary network subscription fees, securing revenue per subscriber after the device is sold. The additional mandatory service allows for secure communication channels and improved web browsing experiences through the compression of data. The BlackBerry AppWorld was first deployed in 2009, offering a shopping solution for BlackBerry consumers and a distribution platform for developers (Site 7). Research in Motion (RIM) was the third-largest smartphone manufacturer in 2010 [15]. The BlackBerry AppWorld acts as marketplace engineer, device and OS manufacturer, and testing and verification partner. By testing in-house, one external party is removed for content inflow. Software suppliers need a certificate from a signing partner in order to submit content. RIM charges an additional monthly fee through network operators to use additional RIM services. Advertisements are outsourced to Yahoo; payments are outsourced to PayPal.

Nokia is the world leader in the mobile phone industry [15]. Nokia started manufacturing mobile phones and mobile infrastructure hardware in 1979 in Finland, and in 1992 the company made the mobile industry its main focus. The smartphone era started in 1996 with the launch of the Nokia Communicator series. This mobile phone featured a proprietary OS and a full keyboard and screen across the length of the device. The OS was changed to Symbian OS in 2001. Symbian OS was acquired by Nokia in 2008 and became an open source OS in 2009. In February 2011, Nokia announced a broad partnership with Microsoft and the adoption of the Windows Mobile OS for their smartphones [25]. Nokia Ovi Store was launched in 2009. For some of its OSs, it has full control, whereas for others it has only partial influence (consortia based or open source). Ovi Store has multiple methods for payment. The mobile network operator Digital River Inc. is a payment broker, as are several SMS brokers. Nokia has a proprietary advertisement program and has two operating systems embedded in its smartphones, both of which are open source. For MeeGo, testing and verification is done in-house with no signing necessary; Symbian and J2ME applications require testing and verification as well as signing by external parties.

The South Korean company Samsung, founded in 1938 as a food export company, became an electronics company in 1969. Samsung entered the smartphone industry in 2003 with the Samsung D700 running Symbian. The company currently produces smartphone devices for all licensed and open source operating systems: Symbian, Windows Mobile, and Android. Samsung was second after Nokia in worldwide mobile phones sales in the third quarter of 2010 [14]. Furthermore, Samsung has developed a proprietary OS (Bada) for all entertainment devices in its product portfolio, which includes televisions, media players, and photo cameras. Samsung Apps is the marketplace that was launched in 2009 to cater to the wide variety of smartphones offered by Samsung, in preparation for the new Bada operating system that will be featured in an ever-increasing range of products. Samsung Apps handles the marketplace, device manufacturing, testing and verification, and payments. One particular issue differentiates Samsung from other parties: Samsung maintains the privilege of creating products that compete with those submitted by software developers and software distributors. Applications that are submitted are required to contain full non-obfuscated source code. Applications that are submitted can be rejected by third parties, also known as liaisons of Samsung. These requirements constitute a potential infringement upon the intellectual property of software suppliers. Samsung Apps contains content not only for OSs like Android, Windows Mobile, and Symbian, but also content for Bada, the OS developed by Samsung.

Google entered the smartphone industry in 2005 through the acquisition of Android Inc., a company that built an OS for mobile phones. Android became an open source project embedded in the Open Handset Alliance, a conglomerate of smartphone industry players working together for design of open industry standards founded in 
2007 (Site 8). The Nexus One, launched in 2010, was the first physical device shipped by Google for consumers since the inception of Android. The device was built by HTC, a device manufacturer, and sold directly via a web shop by Google (Site 9). Android gained the third-largest market share of operating systems for smartphones in 2010 [15]. The Android Market was opened in 2008 featuring free content, and opened for sales in 2009. Developers for the Android Market have been attracted by various Android Developer Challenges (ADC). The first ADC featured five million dollars in prize money as an encouragement for participation (Site 10).

The main thing that differentiates the Google Android Market from the rest is the absence of a testing and verification party or process. Even though Google also manufacturers some devices, this is mainly done by partners. Google designed the Android Market with a free market philosophy whereby the market regulates itself. This may potentially create transaction costs for the end user (see section 3). Google released Android as an open source OS for the Open Handset Alliance, resulting in at least one clone (OPhone) that was detached from Google services by China Mobile and the Google app store was replaced by a proprietary marketplace. Google issues signing certificates for free to anyone who registers as a developer. Google itself supplies the advertisements as well as the payment transaction handling. Even though Android is open source, Google as the main developer can decide when to release code or which manufacturer gets early access to the source code. For Android 3.0 (Honeycomb), Motorola had exclusive early access to the OS during the development of the Motorola Xoom. This put into question the openness of Android and still allows Google to influence handset manufacturers.

Microsoft initially developed a mobile operating system for the PDA industry in 2000 and grew significantly in market share. The market share then fell from the moment that the iPhone was launched by competitor Apple. The Windows Mobile OS market share further declined to 5 percent in favor of BlackBerry OS and Android in 2010 [Gartner, 2010c]. For the newly designed OS product Windows Phone 7, Microsoft launched a marketplace named Windows Phone 7 Marketplace in 2010. The marketplace configuration of Windows Marketplace by Microsoft issues licenses to testing and verification partners as an OS manufacturer, controlling the content quality input. With the Bing network, advertisement solutions for developers are provided and payments are handled by Microsoft. Microsoft is no longer a device manufacturer.

Started by Ilja Laurs in 2004, GetJar is the third-largest application store in download volume with content for smartphones and non-smartphones. GetJar's independent marketplaces offer content that is free for users, and mainly features shareware or time-limited products that can be bought later. The front-end website is directly accessible for consumers, but the back-end is also available as a white-label solution for mobile network operators. To increase the content portfolio with free applications, GetJar incorporated an advertising mechanism for developers. GetJar allows multiple OS content. Testing and verification standards are applied. GetJar also provides advertisement and payment solutions for developers.

\subsection{Comparison of App Store Value Networks}

The individual control of the different elements in the app store ecosystem is presented for the seven companies in question (see Table 4). The influence of the different elements in the app store ecosystem can stem from two sources: ownership and exclusivity. We can distinguish between sole owner (O), shared ownership with a consortium (C), and no ownership. The first dimension is similar to the dimension "control of resource" of Schlagwein, Schoder, and Fischbach [35]. An offering can be exclusive (E), which means there is only one offering allowed for the value network role. For example, you cannot run iOS on smartphones other than Apple's. Some offerings are nonexclusive. Even though Apple is offering software for iPhone, other software developers can offer software, too. However, a company can also have influence (I) through means other than direct exclusive ownership. This typically stems from negotiating access to other owned roles. For example, by giving network operators exclusive distribution of the iPhone, Apple can get a revenue-sharing agreement in return and require additional changes to the network technology to enable visual voicemail.

\subsection{Value-network Configuration Influence Levels}

When comparing the value-network configurations and influence levels in Table 4, we see that all of them are structured differently. Next to being the marketplace engineer, most app store owners have full influence and all have at least limited influence on the role of testing and verification partners. Except for Microsoft, Google, and GetJar, the app store owner is also the main device manufacturer. Six of the seven app store owners offer operating systems, two via a consortium and four as the sole owner. The majority of the app store owners have an influence on the payment broker. In all cases, the software distributor and content provider are not under the control of the app store. The majority also offer advertisement broker services.

Apple has the most value network roles directly under its control (seven), whereas the other app store owners control three to five roles. Except for Google and Apple, all app store owners have no influence over six to seven roles, where Google and Apple have no influence over five and four roles, respectively. Based on this high diversity in influence levels, we hypothesize that the current app store battle is not simply about the open versus closed model. Reality is more complicated, where the so-called open model approach like Google Android also has closed characteristics and vice versa. For example, the open source OS Android can be customized and consequently 
closed for the end user by telecommunication providers or device manufacturers. They may also delay OS upgrades. This could lead, among other things, to the exclusion of specific services and apps or to unchangeable default apps and screens. For the end user, this situation could be even worse than a fair and predictable closed platform. Just as in other value networks, actors try to maximize their influence. An interesting case in point is Apple's announcement in January 2011 that the company wanted to take over the customer payment process of digital editions of newspaper published on, for example, iPhones and iPads, which would severely weaken the position of the newspaper organizations and reduce their role to that of a content developer only.

Table 4: Comparison of value network configurations and influence levels

\begin{tabular}{|c|c|c|c|c|c|c|c|c|c|c|c|c|c|c|}
\hline \multirow{2}{*}{\begin{tabular}{|l} 
Value Network \\
Role Name \\
\end{tabular}} & \multicolumn{2}{|c|}{ Apple } & \multicolumn{2}{|l|}{ RIM } & \multicolumn{2}{|c|}{ Nokia } & \multicolumn{2}{|c|}{ Samsung } & \multicolumn{2}{|c|}{ Google } & \multicolumn{2}{|c|}{ Microsoft } & \multicolumn{2}{|c|}{ GetJar } \\
\hline & 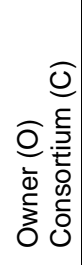 & 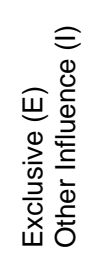 & 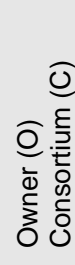 & 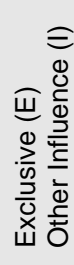 & 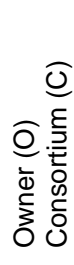 & 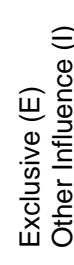 & 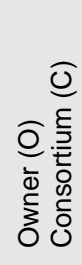 & 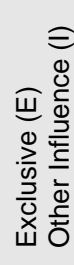 & 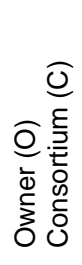 & 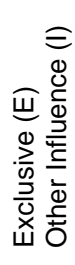 & 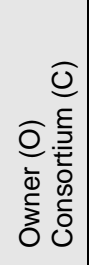 & 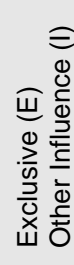 & 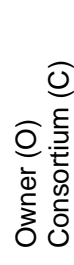 & 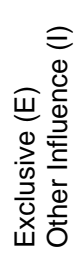 \\
\hline \multicolumn{15}{|l|}{ End User } \\
\hline Network Operator & & $\left.\right|^{*}$ & & $\mathrm{I}^{\#}$ & & & & & & & & & & \\
\hline Payment Broker & $\mathrm{O}$ & $E$ & & & & & 0 & $E$ & $\mathrm{O}$ & $E$ & 0 & $E$ & $\mathrm{O}$ & \\
\hline $\begin{array}{l}\text { Advertisement } \\
\text { Broker }\end{array}$ & $\mathrm{O}$ & & & & $\mathrm{O}$ & & & & $\mathrm{O}$ & & $\mathrm{O}$ & & $\mathrm{O}$ & \\
\hline Marketplace & $\mathrm{O}$ & $E$ & $\mathrm{O}$ & $E$ & $\mathrm{O}$ & $E$ & $\mathrm{O}$ & & $\mathrm{O}$ & & 0 & $E$ & $\mathrm{O}$ & \\
\hline $\begin{array}{l}\text { Operating System } \\
\text { Developer }\end{array}$ & $\mathrm{O}$ & E & O & $\mathrm{E}$ & C & & $\mathrm{O}$ & & C & $\mathrm{E}$ & $\mathrm{O}$ & $E$ & & \\
\hline $\begin{array}{l}\text { Testing \& } \\
\text { Verification Party }\end{array}$ & $\mathrm{O}$ & E & $\mathrm{O}$ & $E$ & $\mathrm{O}$ & $E$ & $\mathrm{O}$ & $E$ & $\mathrm{O}$ & & $\mathrm{O}$ & E & $\mathrm{O}$ & E \\
\hline Signing Partner & $\mathrm{O}$ & $\mathrm{E}$ & & & & & & & $\mathrm{O}$ & & & & & \\
\hline Software Developer & 0 & $1^{\S}$ & & & & & 0 & & 0 & & & & & \\
\hline Content Provider & & $1^{\&}$ & & & & & & & & & & & & \\
\hline \multicolumn{15}{|l|}{ Software Distributor } \\
\hline $\begin{array}{l}\text { Device } \\
\text { Manufacturer }\end{array}$ & $\mathrm{O}$ & $E$ & $\mathrm{O}$ & $E$ & $\mathrm{O}$ & $E$ & $\mathrm{O}$ & $E$ & $\mathrm{O}$ & $I^{\star \star}$ & & $E$ & & \\
\hline
\end{tabular}

Empty Cells means not owner and nonexclusive

* In some countries exclusive ties

** Partially through early access to source code

\# Cooperation for push technology

\& Access to music and video via iTunes Contracts

$\S$ No replication of preinstalled software allowed (such as web browser)

\subsection{App-store-related Business Model Innovation}

When comparing the different app store business models, one can conclude that they are all essentially the same. The business models are about creating an app marketplace platform connecting app developers and app users where the platform owner gets a share of the sales, irrespective of how open or closed the platform is. However, on a more detailed business model (e.g., value proposition) component level, differences can be seen, such as the fact that RIM mainly focuses on business users; Apple's more strict verification approach strengthens its exceptional user experience and quality focus; and Google's approach with different hardware providers and less strict verification supports a best value for money, mass market strategy. We expect that once the sector further matures, this kind of competitive differentiation and segmentation will be increasingly important for each platform owner in order to strengthen its position, just as in other more mature markets and industries.

Moreover, we also expect more apps where the actual usage of the apps and not the installation forms the main source of revenue (i.e., the transition from an app as a product to an app as a service). We already see the emergence of different freemium-based games and services, where the app is being given away for free but where users can pay within the app for extra levels or content, either for a fixed price or on a subscription basis. On a different level, some content providers are not happy with the fact that they have to share a substantial part of their turnover with app store owners and/or the fact that they may lose the direct payment relationship with their customers. Therefore, these content providers may decide to offer their content directly to their consumers with a 
device-independent, browser-based offering, a form of disintermediation (cf. independent musicians not working together with record companies).

New players from different industries have also started offering their own app stores, such as online retailer Amazon, who wants to offer its own walled garden app store for Android phones (with dynamic pricing mechanisms), or consumer electronics companies like Philips with its Net TV app store that also sells its Net TV concept to other consumer electronics companies. The emergence of all these different app stores may also lead to price competition on the app level (cf. competing supermarkets). On the other hand, we also see that current mobile app store owners are trying to broaden their markets by focusing on TV users (cf. Google TV and Apple TV) and generic computer users (cf. Apple's App Store for Mac computers), to name a few.

\subsection{Open Innovations vs. Innovation Economies of Scope}

Innovation in a platform ecosystem is crucial for the viability of the platform and its survival in the face of other competing platforms. The history of information platforms is filled with the battle between various open platforms [42]. According to $\mathrm{Wu}$ [42], every information industry is going through a cycle of initial openness to consolidation and closing until the cycle starts again, either through a disruptive innovation or governmental action. According to the evolutionary theory of innovation [26]-[28], an open platform that allows the free innovation of complementary components has an advantage compared with a centralized planning approach. An app store allows the creation of numerous apps for a platform, applications that the device manufacturer or operating systems developer might not invent by themselves. The opening of certain platform elements for third-party innovation can be called an innovation platform or an open innovation strategy [9].

However, in a platform ecosystem, the control of two or more elements of the ecosystem allows an easier and faster change of these elements compared with a situation where these elements are controlled by different parties who need to coordinate the changes of the elements. An example is Apple, who controls both the iPhone and its iOS operating system. This allowed Apple to invent the concept of multi-touch interfaces more quickly, because it could innovate on both the hardware and software side. We call this advantage of the control of different platform elements innovation economies of scope.

It seems that in newly formed platforms, innovation economies of scope are prevalent because the ecosystems lack stable standards for open innovations. When a platform ecosystem matures, standards emerge and open innovations are possible on top of these platforms. However, from the analysis of the app store value networks, we can see that a mobile platform ecosystem could have a closed, integrated approach that fosters innovation economies of scope for some elements, and at the same time an open innovation strategy for other elements.

\section{Discussion, Contribution and Conclusions}

After the failure of closed model approaches like Compuserve and KPN iMode, and the emergence of the open innovation concept [7], [9], the open model seemed to be the solution for commercializing (mobile) Internet services. However, a few years later, we see that both the relatively closed approach of Apple and the relatively open approach of Google are viable. Apparently the main question for successfully commercializing mobile services is therefore not whether to choose a purely open or closed approach.

We examined the impact of network effects, economies of scale, platform differentiation, quality assurance, and transaction costs on the design of mobile application markets. Our theoretical model allowed for a deeper discussion of the design choices and success factors in the different app store cases. Based on our comparative cross-case analysis of app store value network structures and related influence levels, we conclude that the pure open versus closed model discussion is somewhat outdated. Although open and closed are useful terms for quickly characterizing specific platform business models, one cannot simply characterize Apple's app store as completely closed and that of Google Android as completely open, for example. In other words, for app store owners, it is not simply a binary choice but more a choice within a continuum of how to deploy their app store platform optimally (just as both completely free markets without any regulation and very heavily regulated markets do not seem to be effective [1]). Also, Boudreau's distinction [5] between the platform strategies characterized by a) closed platforms, b) openness to complementary services, and c) relinquishing of the control of the platform is not enough. Our cross-case analysis showed that a mobile platform could be open for some service types and closed for others, depending on the underlying business model.

Both relatively open and closed models have advantages and disadvantages. A more strict testing and verification approach in combination with the existence of only a few different hardware devices may lead to better user experiences (i.e., because of more stable software code) and may prevent diseconomies of scale as well (preventing too many low-quality apps from entering the store makes the app searching process for customers more effective). This in return may lead to improved customer loyalty, which can develop into a strong competitive advantage. Such an approach seems to make sense for a premium brand like Apple. 
On the other hand, a more open model may lead to more competition on both the software and hardware levels with lower prices as a result. There are many producers of Android- or Windows-based phones, generally available for considerably lower prices than iPhone devices, for example. Such an approach may support a strategy focused on becoming the largest app store provider. Based on current developments, we expect that as the mobile applications platform sector matures, the open versus closed models discussion will become less relevant and that, just as in other markets or industries, competitive differentiation and segmentation strategies will become increasingly critical in strengthening the competitive positioning of the different app store platforms. In order to get a better understanding of the competition between the different app store providers, more longitudinal research on the business model dynamics and related innovation will be needed. Our theoretical model and inter-organisational app store value network design may support researchers and practitioners in structuring their strategic analysis. In this paper, our analysis focused on the biggest seven mobile app stores. Future research could cover other app stores, especially independent stores and stores owned by telecommunication providers, online retailers, mobile device manufacturers, and consumer electronics companies.

\section{Websites List}

Site 1: Distimo. Overview of App Stores http://www.distimo.com/appstores/

Site 2: Gartner. Gartner says consumers will spend $\$ 6.2$ billion in mobile application stores in 2010 http://www.gartner.com/it/page.jsp?id=1282413

Site 3: Apple. Apple's App Store downloads top 10 billion http://www.apple.com/pr/library/2011/01/22appstore.html

Site 4: Nokia. Ovi Store statistics

http://www.forum.nokia.com/Distribute/Ovi Store statistics.xhtml

Site 5: The Indepent. 100 million app download milestone just the beginning says Samsung http://www.independent.co.uk/life-style/gadgets-and-tech/100-million-app-download-milestone-just-the-beginningsays-samsung-2255354.html

Site 6: AndroidLib. Android Market statistics from AndroidLib http://www.androlib.com/appstats.aspx

Site 7: Research In Motion. BlackBerry App World http://us.blackberry.com/apps-software/appworld/

Site 8: Open Handset Alliance http://www.openhandsetalliance.com/oha overview.html

Site 9: Google. Corporate information http://www.google.com/int//en/corporate/

Site 10: Google. Android Developer Challenge I Gallery http://code.google.com/android/adc/adc gallery/

\section{References}

[1] H. Achterhuis, De utopie van de vrije markt (Dutch). Rotterdam: Uitgeverij Lemniscaat, 2010.

[2] G. A. Akerlof, The market for "lemons": Quality uncertainty and the market mechanism, The Quarterly Journal of Economics, vol. 84, no. 3, pp. 488-500, 1970.

[3] M. M. Al-Debei and D. Avison, Developing a unified framework of the business model concept, European Journal of Information Systems, vol. 19, no. 3, pp. 359-376, 2010.

[4] K. Andrew. (2011, March) BlackBerry App World doing 3 million downloads a day, Pocket Gamer.Biz. [Online]. Available: http://www.pocketgamer.biz/r/PG.Biz/BlackBerry+App+World/news.asp?c=28631.

[5] K. Boudreau, Open platform strategies and innovation: Granting access vs. devolving control, Management Science, vol. 56, no. 10, pp. 1849-1872, 2010.

[6] H. Bouwman, E. Faber, T. Haaker, B. Kijl, and M. De Reuver, Conceptualizing the STOF Model, in Mobile Service Innovation and Business Models, H. Bouwman, T. Haaker, and H. De Vos, Eds. Berlin: Springer Verlag, 2008, pp. 31-70.

[7] H. Chesbrough, Open business models: How to thrive in the new innovation landscape, MA: Harvard Business School Press, 2006. 
[8] H. Chesbrough and R. S. Rosenbloom, The role of the business model in capturing value from innovation: evidence from Xerox Corporation's technology spin-off companies, Industrial and Corporate Change, vol. 11, no. 3, pp. 529-555, 2002.

[9] H. W. Chesbrough, Open innovation: The new imperative for creating and profiting from technology, MA: Harvard Business Press, 2003.

[10] M. De Reuver, Governing mobile service innovation in co-evolving value networks, Delft: Delft University of Technology, 2009.

[11] C. Dellarocas, Immunizing online reputation reporting systems against unfair ratings and discriminatory behavior, in Proceedings of the 2nd ACM conference on Electronic commerce, Minneapolis, 2000, pp. 150-157.

[12] D. S. Evans and R. Schmalensee, The industrial organization of markets with two-sided platforms, Competition Policy International, vol. 3, no. 1, pp. 151-179, 2007.

[13] E. J. Friedman and P. Resnick, The social cost of cheap pseudonyms, Journal of Economics \& Management Strategy, vol. 10, no. 2, pp. 173-199, 2001.

[14] Gartner. (2010, August) Gartner says worldwide mobile device sales grew 13.8 percent in second quarter of 2010, but competition drove prices down. [Online]. Available: http://www.gartner.com/it/page.jsp?id=1421013.

[15] Gartner. (2011, April) Press Release: Gartner Says Android to Command Nearly Half of Worldwide Smartphone Operating System Market by $2012 . \quad$ [Online]. Available: http://www.gartner.com/it/page.jsp?id=1622614.

[16] V. Gonçalves, N. Walravens, and P. Ballon, "How about an App Store?" Enablers and constraints in platform strategies for mobile network operators, in Proceedings of International Conference on Mobile Business (ICMB) and Global Mobility Roundtable (GMR), Athens, Greece, 2010, pp. 66-73.

[17] J. Gordijn and H. Akkermans, Designing and evaluating e-business models, Intelligent Systems, IEEE, vol. 16, no. 1, pp. 11-17, 2001

[18] J. Hedman and T. Kalling, The business model concept: theoretical underpinnings and empirical illustrations, European Journal of Information Systems, vol. 12, no. 1, pp. 49-59, Mar 2003.

[19] A. Jusang, R. Ismail, and C. Boyd, A survey of trust and reputation systems for online service provision, Decision Support Systems, vol. 43, no. 2, pp. 618-644, 2007.

[20] M. L. Katz and C. Shapiro, Systems competition and network effects, The Journal of Economic Perspectives, vol. 8, no. 2, pp. 93-115, 1994.

[21] J. Kincaid. (2011, January) Amazon's disruptive android app store now open to developers. [Online]. Available: http://techcrunch.com/2011/01/05/amazon-android-app-store-2/.

[22] E. F. Konczal, Models are for managers, not mathematicians, Journal of Systems Management, vol. 26, no. 1, pp. 12-15, 1975.

[23] F. Lin and W. Ye, Operating System Battle in the Ecosystem of Smartphone Industry, in Information Engineering and Electronic Commerce, 2009. International Symposium on, 2009, pp. 617-621.

[24] J. Magretta, Why business models matter, Harvard business review, vol. 80, pp. 86-93, May 2002.

[25] Microsoft, Press Release. (2011, February) Nokia and Microsoft Announce Plans for a Broad Strategic Partnership to Build a New Global Mobile Ecosystem. [Online]. Available: http://www.microsoft.com/presspass/press/2011/feb11/02-11partnership.mspx.

[26] R. R. Nelson and S. G. Winter, In search of useful theory of innovation, Research policy, vol. 6, no. 1, pp. 36-76, 1977.

[27] R. R. Nelson and S. G. Winter, An Evolutionary Theory of Economic Change. Cambridge, MA: Belknap Press of Harvard University Press, 1982.

[28] R. R. Nelson and S. G. Winter, Evolutionary theorizing in economics, Journal of Economic Perspectives, vol. 16, no. 2, pp. 23-46, 2002.

[29] A. Osterwalder and Y. Pigneur, Business Model Generation: A Handbook for Visionaries, Game Changers, and Challengers, NJ: Wiley, 2009.

[30] A. Osterwalder, Y. Pigneur, and C. Tucci, Clarifying business models: Origins, present, and future of the concept, Communications of the Association for Information Systems, vol. 16, no. 1, pp. 1-25, 2005.

[31] J. Peppard and A. Rylander, From value chain to value network: Insights for mobile operators, European Management Journal, vol. 24, no. 2-3, pp. 128-141, 2006.

[32] M. E. Porter, Strategy and the Internet, Harvard Business Review, vol. 79, pp. 63-76, 2001.

[33] P. Resnick, K. Kuwabara, R. Zeckhauser, and E. Friedman, Reputation systems, Communications of the ACM, vol. 43, no. 12, pp. 45-48, 2000.

[34] J.-C. Rochet and J. Tirole, Platform competition in two-sided markets, Journal of the European Economic Association, vol. 1, no. 4, pp. 990-1029, 2003.

[35] D. Schlagwein, D. Schoder, and K. Fischbach, Openness of information resources - A framework-based comparison of mobile platforms, in Proceedings of 18th European Conference on Information Systems Pretoria, South Africa, 2010, pp 1-16.

[36] B. F. Schmid and M. A. Lindemann, Elements of a reference model for electronic markets, in Proceedings of the Thirty-First Hawaii International Conference on System Sciences, Hawaii, 1998, pp. 193-201.

[37] P. Stähler, Geschäftsmodelle in der digitalen Ökonomie. Merkmale, Strategien und Auswirkungen, Lohmar: Josef Eul Verlag, 2002.

[38] H. R. Varian, Market for information goods, Discussion paper no. 99-e-9, Institute of Monetary and Economic Studies, Bank of Japan, Tokyo, Japan 1999. 
[39] H. Weigand, P. Johannesson, B. Andersson, M. Bergholtz, A. Edirisuriya, and T. Ilayperuma, Strategic analysis using value modeling-the c3-value approach, in Proceedings of the Hawaii International Conference on System Sciences, 2007, pp. 2906.

[40] O. Williamson, Transaction cost economics, in Handbook of new institutional economics (C. Ménard and M. M. Shirley, Eds.), 2005, pp. 41-65.

[41] O. E. Williamson, Markets and hierarchies: some elementary considerations, The American Economic Review, vol. 63, no. 2, pp. 316-325, 1973.

[42] T. Wu, The Master Switch: The Rise and Fall of Information Empires. New York: Knopf, 2010. 